\title{
A role for antizyme inhibitor in cell proliferation
}

\author{
Tania M. Silva ${ }^{1,4} \cdot$ Helena Cirenajwis ${ }^{1,5} \cdot$ Heather M. Wallace ${ }^{1,2} \cdot$ Stina Oredsson $^{1}$. \\ Lo Persson ${ }^{3}$
}

Received: 19 November 2014 / Accepted: 6 March 2015 / Published online: 27 March 2015

(c) The Author(s) 2015. This article is published with open access at Springerlink.com

\begin{abstract}
The polyamines are important for a variety of cellular functions, including cell growth. Their intracellular concentrations are controlled by a complex network of regulatory mechanisms, in which antizyme (Az) has a key role. Az reduces the cellular polyamine content by down-regulating both the enzyme catalysing polyamine biosynthesis, ornithine decarboxylase (ODC), and the uptake of polyamines. The activity of $\mathrm{Az}$ is repressed by the binding of a protein, named Az inhibitor (AzI), which is an enzymatically inactive homologue of ODC. Two forms of AzI have been described: AzI1, which is ubiquitous, and AzI2 which is expressed in brain and testis. In the present study, we have investigated the role of AzI1 in polyamine homeostasis and cell proliferation in breast cancer cells. The results obtained showed that
\end{abstract}

Handling Editor: C. Schiene-Fischer.

Tania M Silva and Helena Cirenajwis have equally contributed to this work.

Lo Persson

Lo.Persson@med.lu.se

1 Department of Biology, Lund University, Lund, Sweden

2 Division of Applied Medicine, University of Aberdeen, Polwarth Building, Foresterhill, Aberdeen, UK

3 Department of Experimental Medical Science, Lund University, Lund, Sweden

4 Present Address: Laboratory of Microbiology and Immunology of Infection, Institute for Molecular and Cell Biology, Porto University, Porto, Portugal

5 Present Address: Division of Oncology and Pathology, Department of Clinical Sciences, Lund University, Lund, Sweden the cellular content of AzI increased transiently after induction of cell proliferation by diluting cells in fresh medium. Inhibition of polyamine biosynthesis induced an even larger increase in the cellular AzI content, which remained significantly elevated during the 7-day experimental period. However, this increase was not a consequence of changes in cell cycle progression, as demonstrated by flow cytometry. Instead, the increase appeared to correlate with the cellular depletion of polyamines. Moreover, induced overexpression of AzI resulted in an increased cell proliferation with a concomitant increase in ODC activity and putrescine content. During mitosis, AzI1 was localised in a pattern that resembled that of the two centrosomes, confirming earlier observations. Taken together, the results indicate that AzI fulfils an essential regulatory function in polyamine homeostasis and cell proliferation.

Keywords Antizyme inhibitor $1 \cdot$ Polyamines - Ornithine decarboxylase $\cdot$ Cell proliferation $\cdot$ Breast cancer
Abbreviations
AG Aminoguanidine
$\mathrm{Az} \quad$ Antizyme
AzI Antizyme inhibitor
BrdUrd Bromodeoxyuridine
DFMO Difluoromethylornithine
ECL Enhanced chemiluminescence
FITC Fluorescein isothiocyanate
LI Labelling index
ODC Ornithine decarboxylase
PBS Phosphate-buffered saline
PI Propidium iodide
$\mathrm{RM}_{\text {zero }} \quad$ Relative movement zero
uCC Upstream conserved coding region 


\section{Introduction}

Polyamines are recognised as necessary growth factors in all cells, including cancer cells (Wallace et al. 2003; Gerner and Meyskens 2004; Nowotarski et al. 2013). Perturbation of intracellular polyamine content in mammalian cells has dramatic effects on cell proliferation and cell death/apoptosis. Thus, a complex of elaborate mechanisms, affecting synthesis, degradation as well as membrane transport, has evolved for the control of polyamine homeostasis (Persson 2009; Pegg and Casero 2011). Ornithine decarboxylase (ODC) is a key regulatory protein catalysing the first and rate-limiting step in polyamine biosynthesis. This enzyme is strictly regulated by antizyme (Az), which binds to ODC with a high affinity at the monomeric level, inhibiting the formation of the active ODC homodimer and targeting it for ubiquitin-independent degradation by the $26 \mathrm{~S}$ proteasome (Kahana 2009; Murai et al. 2011).

In addition, Az inhibits the cellular uptake of extracellular polyamines (Mitchell et al. 1994; Suzuki et al. 1994). The cellular content of $\mathrm{Az}$ is partly regulated by polyamines, which stimulate its synthesis by a unique mechanism involving ribosomal frame-shifting (Rom and Kahana 1994; Matsufuji et al. 1995). At least three different mammalian isoforms of Az (Az1-Az3) have been identified, of which Az1 and Az2 are ubiquitously expressed, whereas Az3 is testis-specific (Kahana 2009). All three Az isoforms are capable of inhibiting ODC activity and polyamine uptake, but only Az1 and Az2 can target ODC for degradation (Kahana 2009).

In addition to $\mathrm{Az}$, cells contain another protein with a putative role in polyamine homeostasis. This protein was first discovered in rat liver by the potential to reactivate Azinhibited ODC and was thus given the name of Az inhibitor (AzI) (Fujita et al. 1982). AzI, which is an enzymatically inactive homologue of ODC, binds to Az with higher affinity than does ODC and consequently releases ODC from its inactive ODC-Az complex (Fujita et al. 1982). By binding to Az, AzI also prevents the effects of Az on ODC degradation and cellular uptake of polyamines (Kahana 2009; Murai et al. 2011). Keren-Paz et al. (2006) demonstrated that NIH3T3 cells overexpressing AzI had increased ODC activity and polyamine uptake, and exhibited improved cell proliferation. Moreover, these cells gave rise to tumours when injected into nude mice (Keren-Paz et al. 2006), whereas knockdown of AzI using siRNA or shRNA decreased cell proliferation both in vitro and in vivo (Choi et al. 2005; Keren-Paz et al. 2006; Olsen et al. 2012). Mutant mice with both AzI alleles disrupted, died close to birth and displayed abnormal liver morphology and perturbed polyamine homeostasis (Tang et al. 2009). Interestingly, AzI has also been shown to be up-regulated in a number of human cancers (Jung et al. 2000; Schaner et al. 2003; van Duin et al. 2005; Chin et al. 2007; Olsen and Zetter 2011).

In spite of its putative role in polyamine homeostasis and its cell proliferation-promoting effects, information on the regulation and cellular function of AzI is relatively sparse. Nevertheless, a close correlation between cell proliferation, ODC and AzI has been demonstrated (Murakami et al. 1989; Nilsson et al. 2000; Murakami et al. 2009). Results indicate that AzI may have other functions besides being involved in polyamine homeostasis. Zetter and colleagues reported that AzI reduced the turnover of cyclin D, as well as induced centrosome overduplication (Kim et al. 2006; Mangold et al. 2008). A co-localisation of Az1 and AzI to the centrosome during mitosis was confirmed by Murakami et al. (2009). In addition to the ubiquitously present AzI, a closely related protein, termed AzI2, is expressed in brain and testis (Pitkanen et al. 2001; Lopez-Contreras et al. 2006). Thus, the first AzI discovered is sometimes referred to as AzI1. Similar to AzI1, AzI2 neutralises the effects of $\mathrm{Az}$ on ODC and the cellular uptake of polyamines (LopezContreras et al. 2008; Snapir et al. 2008). In addition, Kanerva et al. (2010) presented results indicating that AzI2 is involved in the regulation of vesicular transport within the cell.

In the present study, we investigated the role of AzI1 (referred to as AzI) in polyamine homeostasis and cell proliferation in breast cancer cells. The results show that AzI expression varied in relation to cell proliferation and polyamine content. Moreover, induced overexpression of AzI resulted in an increased cell proliferation with a concomitant increase in ODC activity and putrescine content. AzI was shown to be localised in a centrosomal pattern during mitosis, confirming earlier observations of a co-localisation of AzI with centrosomes (Mangold et al. 2008; Murakami et al. 2009).

\section{Materials and methods}

Cell culture medium components were purchased from Biochrom, Berlin, Germany. Tissue culture plastics were acquired from Nunc, Roskilde, Denmark. Phosphatebuffered saline (PBS: $8 \mathrm{~g} / \mathrm{L} \mathrm{NaCl}, 0.2 \mathrm{~g} / \mathrm{L} \mathrm{KCl}, 1.15 \mathrm{~g} / \mathrm{L}$ $\mathrm{Na}_{2} \mathrm{HPO}_{4}, 0.2 \mathrm{~g} / \mathrm{L} \mathrm{KH}_{2} \mathrm{PO}_{4}, \mathrm{pH}$ 7.3) was purchased from Oxoid Ltd., Basingstoke, Hampshire, UK. Nonidet P-40 was purchased from VWR, Lund, Sweden. Insulin and propidium iodide (PI) were obtained from Sigma, Stockholm, Sweden. Dimethyl sulphoxide (DMSO) was acquired from Merck KGaA, Darmstadt, Germany. L- $\left[1-{ }^{14} \mathrm{C}\right]$ Ornithine $(1.9 \mathrm{GBq} / \mathrm{mmol})$ was purchased from New England Nuclear Du Pont, Scandinavia AB, Stockholm, Sweden. Bromodeoxyuridine (BrdUrd) and the primary monoclonal antibody against BrdUrd (Clone: Bu20a), as well as the 
secondary fluorescein isothiocyanate (FITC)-conjugated antibody and the secondary horseradish peroxidase-conjugated goat anti-mouse $\operatorname{IgG}$ antibody, were all purchased from DAKO, Glostrup, Denmark. Hybond enhanced chemiluminescence (ECL) nitrocellulose membrane and ECL ${ }^{\mathrm{TM}}$ Advance Blotting Detection Kit (Amersham Biosciences) were purchased from GE Healthcare, Uppsala, Sweden. Geneticin and all components of the NuPAGE Novex Pre-Cast Gel System used for Western blot were obtained from Invitrogen Corporation, Carlsbad, CA, USA. The antibody against $\beta$-actin was purchased from Abcam, Cambridge, UK. The monoclonal antibody against rat AzI1 was kindly provided by Dr. Senya Matsufuji and Dr. Yasuku Murakami, Tokyo, Japan. Gene Pulser Cyvettes $(0.4$ and $0.1 \mathrm{~cm}$ ) were purchased from Bio-Rad, Hercules, CA, USA. The mammalian expression vector pCl-neo was purchased from Promega Corporation, Madison, WI, USA. The Nucleo Spin Extract Kit was obtained from Clonetech Laboratories, Inc., Mountainview, CA, USA. The agarose gels were obtained from Bio-Rad Laboratories, Hercules, CA, USA. The Genelute HP plasmid midi-prep kit was purchased from Sigma-Aldrich Sweden AB, Stockholm, Sweden. Restriction enzymes and T4 DNA ligase were purchased from Fermentas GMBH, Helsingborg, Sweden. The oligos for PCR were obtained from TAG, Copenhagen, Denmark. Difluoromethylornithine (DFMO) was purchased from Ilex-Oncology, San Antonio, Texas, USA. SAM486A was a kind gift from Novartis, Basel, Switzerland.

\section{Drug stock solutions}

Stock solutions of SAM486A (2 $\mathrm{mM})$, aminoguanidine $(\mathrm{AG}, 50 \mathrm{mM})$, putrescine $(50 \mathrm{mM})$ and spermidine $(50 \mathrm{mM})$ were made in PBS. DFMO was dissolved in Millipore water to obtain a concentration of $0.5 \mathrm{M}$ after adjusting $\mathrm{pH}$ to 7.2. All solutions were sterile-filtered and used in the experiments at final concentrations of: SAM486A $(20 \mu \mathrm{M})$, AG $(1 \mathrm{mM})$, putrescine $(100 \mu \mathrm{M})$, spermidine $(50 \mu \mathrm{M})$ and DFMO $(1 \mathrm{mM})$.

\section{Cell culture}

The human breast carcinoma cell line JIMT-1 (ACC589) was purchased from the German Collection of Microorganisms and Cell Cultures, DSMZ (Braunschweig, Germany) and was cultured in DMEM/Ham's F12 medium supplemented with $10 \%$ foetal bovine serum, non-essential amino acids $(1 \mathrm{mM})$, insulin $(10 \mu \mathrm{g} / \mathrm{ml})$, penicillin $(100 \mathrm{U} / \mathrm{ml})$ and streptomycin $(100 \mu \mathrm{g} / \mathrm{ml})$. The human breast carcinoma cell line MCF-7 (HTB22) was obtained from the American Type Culture Collection (Manassas, VA, USA) and was cultured in RPMI 1640 medium supplemented with $10 \%$ foetal bovine serum, non-essential amino acids ( $1 \mathrm{mM})$, insulin $(10 \mu \mathrm{g} / \mathrm{ml})$, penicillin $(100 \mathrm{U} / \mathrm{ml})$ and streptomycin $(100 \mu \mathrm{g} / \mathrm{ml})$. Both cell lines were cultured as monolayers at $37{ }^{\circ} \mathrm{C}$ in a humidified incubator with $5 \% \mathrm{CO}_{2}$ in air. The JIMT-1 cell line, having a doubling time of approximately $24 \mathrm{~h}$, was sub-cultured twice a week, while the MCF-7 cell line, with a doubling time of approximately $34 \mathrm{~h}$, was subcultured once a week. In all experiments, plateau phase cells were reseeded to a lower cell density $(30,000$ cells/ $\mathrm{cm}^{2}$ ). The cells were seeded in the absence or presence of DFMO, SAM486A, DFMO/putrescine or DFMO/spermidine. In experiments using spermidine, AG was added to inhibit any activity of polyamine oxidases present in the bovine serum. The cells were harvested by trypsinisation and the cell number was determined by counting in a hemocytometer at times indicated in the figures. The cells were pelleted and stored at $-80{ }^{\circ} \mathrm{C}$ until further analysis.

\section{ODC activity assay}

The cells were sonicated in ice-cold $0.1 \mathrm{M}$ Tris- $\mathrm{HCl}(\mathrm{pH}$ 7.5) containing $0.1 \mathrm{mM}$ EDTA and $2.5 \mathrm{mM}$ dithiothreitol. The ODC activity was determined by measuring the release of $\left[{ }^{14} \mathrm{C}\right] \mathrm{CO}_{2}$ from carboxyl-labelled L-ornithine, in the presence of saturating levels of pyridoxal 5-phosphate $(0.1 \mathrm{mM})$ and L-ornithine $(0.2 \mathrm{mM})$ (Jänne and WilliamsAshman 1971).

\section{Polyamine analysis}

Chromatographic separation and quantitative determination of the polyamines in cell extracts in $0.2 \mathrm{M}$ perchloric acid were carried out using a HPLC (Hewlett Packard 1100) with $\theta$-phthaldialdehyde as the reagent essentially as previously described (Seiler and Knödgen 1980).

\section{Cell cycle progression analysis}

Cells were seeded in the absence or presence of DFMO and harvested by trypsinisation every second hour for up to $24 \mathrm{~h}$ after seeding. Thirty minutes before harvesting, BrdUrd $(5 \mu \mathrm{M})$ was added to the medium of the cells. The cells were collected and fixed in ice-cold $70 \%$ ethanol and stored at $-20{ }^{\circ} \mathrm{C}$ until further analysis. At the time of analysis, BrdUrd incorporated into DNA was labelled with primary BrdUrd antibodies followed by secondary FITCconjugated antibodies, and DNA was stained with PI, as recently described (Silva et al. 2013). The labelled cells were analysed by flow cytometry using an Ortho Cytoron Absolute flow cytometer (Ortho Diagnostic Systems, Raritan, NJ, USA). The MultiCycle ${ }^{\circledR}$ software program (Phoenix Flow Systems, CA, USA) was used for evaluation of the data with respect to DNA and BrdUrd contents. Cell cycle progression during the $24 \mathrm{~h}$ after seeding was 
monitored by following changes in relative movement zero $\left(\mathrm{RM}_{\text {zero }}\right)$ and labelling index (LI) (Fredlund and Oredsson 1996).

\section{Western blot analysis of AzI}

The cells were diluted in sample buffer $(62.5 \mathrm{mM}$ Tris-HCl, pH 6.8, $20 \%$ glycerol, $2 \%$ SDS, $5 \%$ $\beta$-mercaptoethanol and $0.5 \%$ bromophenol blue) and sonicated, followed by immediate boiling for $6 \mathrm{~min}$. The samples were stored at $-20^{\circ} \mathrm{C}$ until analysis. Aliquots containing 50,000 or 100,000 cells were loaded and separated on 4-12\% acrylamide Bis-Tris gels (Invitrogen) using the Xcell Sure Lock ${ }^{\mathrm{TM}}$ Mini-Cell System (Invitrogen). The separated proteins were transferred to nitrocellulose membranes using the iBlot ${ }^{\mathrm{TM}}$ Dry Blotting System (Invitrogen). Thereafter, the membranes were blocked in $5 \%$ non-fat dry milk in PBS-T (PBS containing $0.05 \%$ Tween 20) and incubated overnight with the primary antibody against rat AzI $(1: 50,000)$ at $4{ }^{\circ} \mathrm{C}$. Following washing in PBS-T, the membranes were incubated with the secondary horseradish peroxidase-conjugated goat anti-mouse IgG antibody $(1: 20,000)$ in PBS-T for $1 \mathrm{~h}$ at room temperature. The bands were detected with the ECL ${ }^{\mathrm{TM}}$ Advance Blotting Detection Kit. The ChemiDoc XRS system and the Quantity One software (both from Bio-Rad Laboratories Inc., Hercules, CA, USA) were used for imaging and data analysis. Actin was used as a loading control.

\section{Stable transfection of AzI}

The coding region of human AzI1 was subcloned from pcDNA3.1-AzI (kindly provided by Leif Andersson, Helsinki) into the mammalian expression vector pCI-neo. Exponentially growing JIMT-1 and MCF-7 cells were transfected with the pCI-neo/AzI construct or the pCI-neo empty vector using a Gene Pulser ${ }^{\circledR}$ II (Bio-Rad, CA, USA). Stable transfectants were selected by addition of geneticin $(0.5 \mathrm{mg} / \mathrm{ml})$ to the cell culture medium.

\section{Immunofluorescence microscopy}

Cells were cultured on sterile poly-L-lysine-coated glass slides for $48 \mathrm{~h}$. After fixation in $3.7 \%$ paraformaldehyde (in PBS) for $15 \mathrm{~min}$ at room temperature and subsequent washing in PBS, the slides were blocked in $5 \%$ non-fat dry milk in PBS-T for $1 \mathrm{~h}$ at room temperature. The cells were incubated with the primary AzI antibody diluted 1:10,000 in PBS-T overnight at $4{ }^{\circ} \mathrm{C}$. After washing, the cells were incubated for $1 \mathrm{~h}$ with the Alexa Fluor 488 Goat Anti-mouse antibody (Invitrogen) (diluted 1:500 in PBS$\mathrm{T}$ ), at room temperature. Slides were counterstained with bisbenzimide and finally washed in PBS before mounting.
Fluorescence-labelled cells were photographed using an Olympus/Nikon epifluorescence microscope (Olympus Optical Co. Ltd., Japan) equipped with a digital camera (Nikon Imaging Japan Inc., Japan). The final images shown were obtained by overlaying AzI- and bisbenzimide-stained pictures using Adobe Photoshop 8.0.1 (Adobe Systems Incorporated, San Jose, California, USA).

\section{Statistical analysis}

Values are expressed as mean \pm SEM. Students' $t$ test was used for statistical evaluation and $p<0.05$ was considered as significant.

\section{Results}

\section{Effects of DFMO on polyamine homeostasis}

Initially, we analysed the effects of DFMO on JIMT-1 breast cancer cells. Treatment with DFMO significantly reduced the proliferation of JIMT-1 cells seeded in fresh medium (Fig. 1a). The late effect of DFMO on cell proliferation was preceded by changes in the polyamine metabolism, seen as early as $24 \mathrm{~h}$ after start of treatment (Fig. 1). ODC activity (which was transiently increased after reseeding) and intracellular polyamine content were decreased markedly by treatment with DFMO (Fig. 1b, e). In contrast to putrescine, which was depleted entirely after $24 \mathrm{~h}$ of DFMO treatment, the spermidine concentration continued to decrease to about $10 \%$ of the control value at $48 \mathrm{~h}$ of treatment, whereas spermine was not affected significantly by DFMO treatment (Fig. 1e). Interestingly, the cellular content of AzI increased transiently after reseeding the cells in fresh medium (Fig. 1c, d). In parallel with the early changes in polyamine metabolism, the AzI level had increased dramatically after $24 \mathrm{~h}$ of DFMO treatment and remained elevated during the entire treatment cycle of $168 \mathrm{~h}$, although a $50 \%$ reduction was observed from day 5 (Fig. 1c, d).

\section{Effects of DFMO on cell cycle progression}

The AzI content has been shown to vary during the cell cycle, with peaks in the $\mathrm{G}_{1}$ and $\mathrm{G}_{2} / \mathrm{M}$ phases (Murakami et al. 2009). Since the AzI content was increased significantly in JIMT-1 cells as early as $24 \mathrm{~h}$ of DFMO treatment, we decided to investigate whether this increase was a consequence of DFMO affecting the cell cycle progression. The cells used for seeding were partly synchronised and approximately $80 \%$ (results not shown) were in $\mathrm{G}_{0} / \mathrm{G}_{1}$ phase (plateau phase cells). Small treatment-induced effects on the partially synchronised cell cycle progression may 
(a)

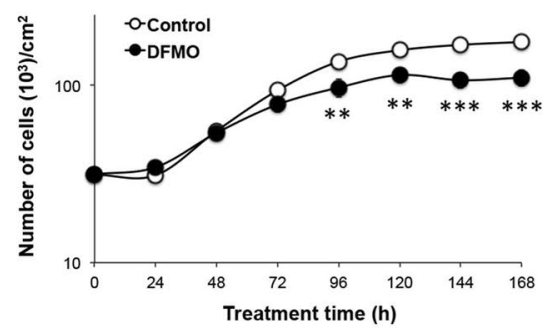

(b)

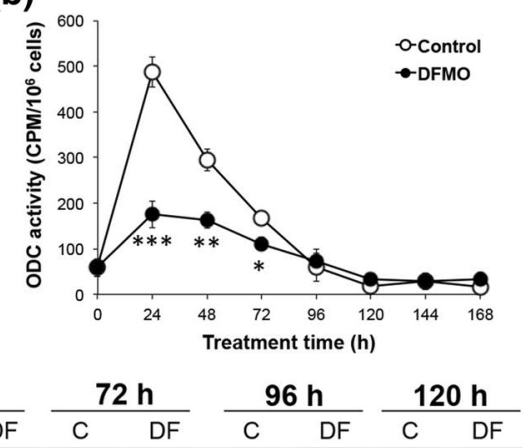

(c)
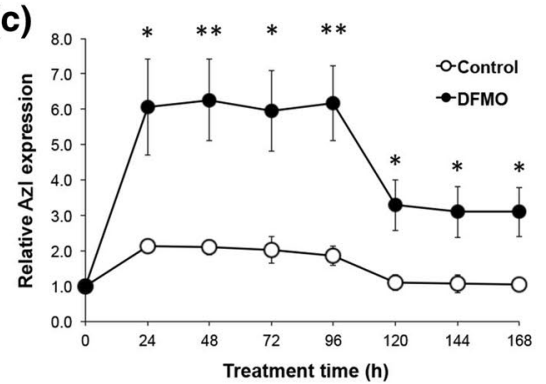

$\frac{144 \mathrm{~h}}{\mathrm{C} D \mathrm{DF}} \frac{168 \mathrm{~h}}{\mathrm{C} D \mathrm{DF}}$

(d)

$0 \mathrm{~h} \frac{24 \mathrm{~h}}{\mathrm{C} D \mathrm{DF}} \frac{48 \mathrm{~h}}{\mathrm{C} D \mathrm{DF}} \frac{72 \mathrm{~h}}{\mathrm{C} D \mathrm{DF}} \frac{96 \mathrm{~h}}{\mathrm{C} D \mathrm{DF}} \frac{120 \mathrm{~h}}{\mathrm{C} D \mathrm{DF}} \frac{144 \mathrm{~h}}{\mathrm{C} D \mathrm{DF}} \frac{168 \mathrm{~h}}{\mathrm{C} D \mathrm{DF}}$

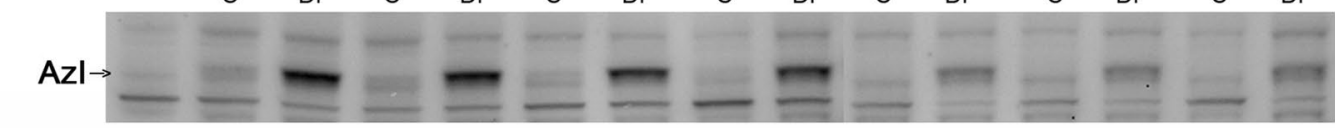

$\beta$-actin

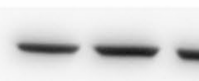

(e)
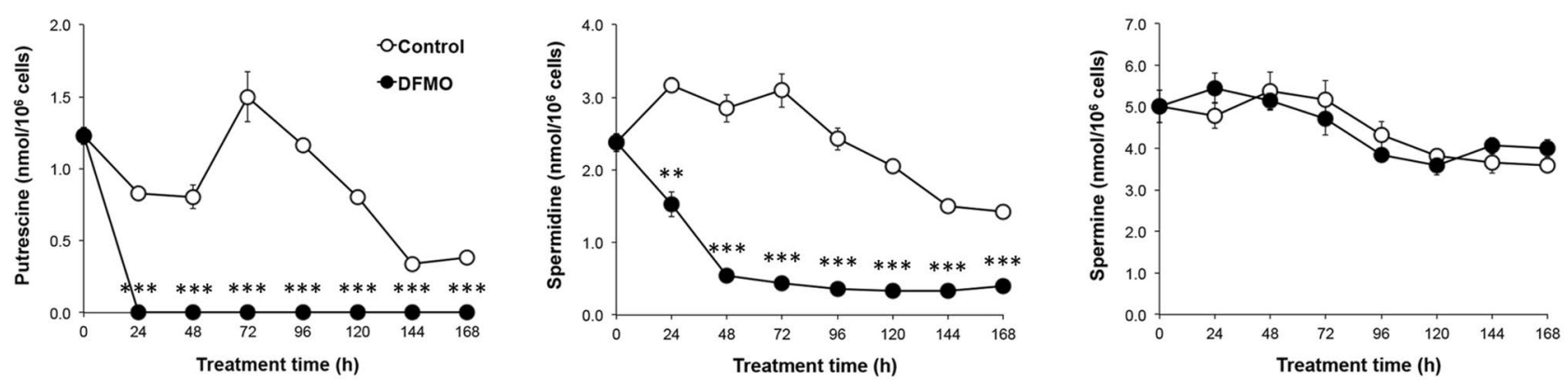

Fig. 1 Long-term effects of DFMO on cell proliferation, ODC activity, AzI level and polyamine content in JIMT-1 cells. Cells were seeded in the absence or presence of $1 \mathrm{mM}$ DFMO (DF). a The cells were harvested for analyses every $24 \mathrm{~h}$ for up to $168 \mathrm{~h}$ by trypsinisation and the cell number was determined by using a hemocytometer. Cell pellets were prepared and used for various analyses. b ODC activity was determined by a radiometric assay. $\mathbf{c}$ and $\mathbf{d}$ AzI was determined and quantified by Western blot (d) and the data from three experiments were densitometrically scanned and presented as relative AzI expression (c). e Putrescine, spermidine and spermine contents were determined by HPLC. Values are mean \pm SEM $(n=3-7)$. When not visible, the SEM bars are covered by the symbols. ${ }^{*} p<0.05 ; * * p<0.01 ; * * p<0.001$ (compared to controls)

then it increased to a maximum at $8 \mathrm{~h}$ after seeding. During this time, the LI was $10 \%$ (Fig. 2b). Taken together, these data imply that the $10 \%$ of cells in S phase were located mainly at the end of $\mathrm{S}$ phase at the time of seeding. The rapid drop in $\mathrm{RM}_{\text {zero }}$ between 8 and $16 \mathrm{~h}$ after seeding is caused by the massive inflow of cells from $G_{1}$ phase into $S$ phase, due to the partially synchronous proliferation of the cells (Fig. 2a). This is reflected in a large increase in LI during the same time period (Fig. 2b). DFMO treatment had no effect on this early cell cycle progression (Fig. 2a, b). Thus, the increased AzI level found after $24 \mathrm{~h}$ of treatment (Fig. 1c, d) was not caused by a DFMO-induced effect on early cell cycle progression. Instead, it is conceivable that the induction of AzI after treatment with DFMO was related to the decrease in cellular putrescine and/or spermidine content (Fig. 2e). 

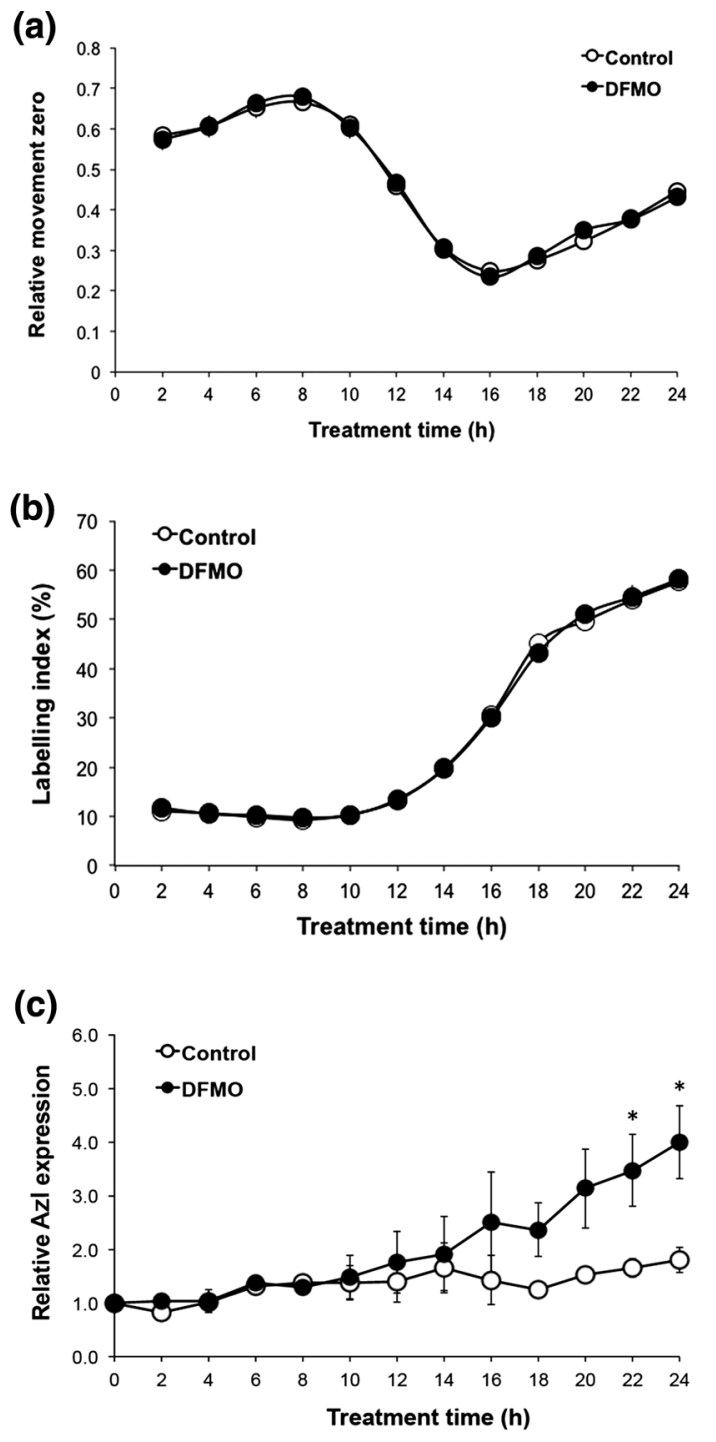

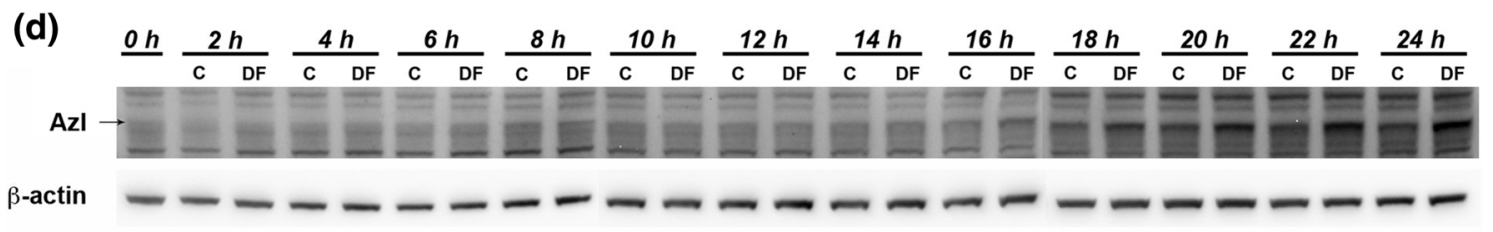

(e)
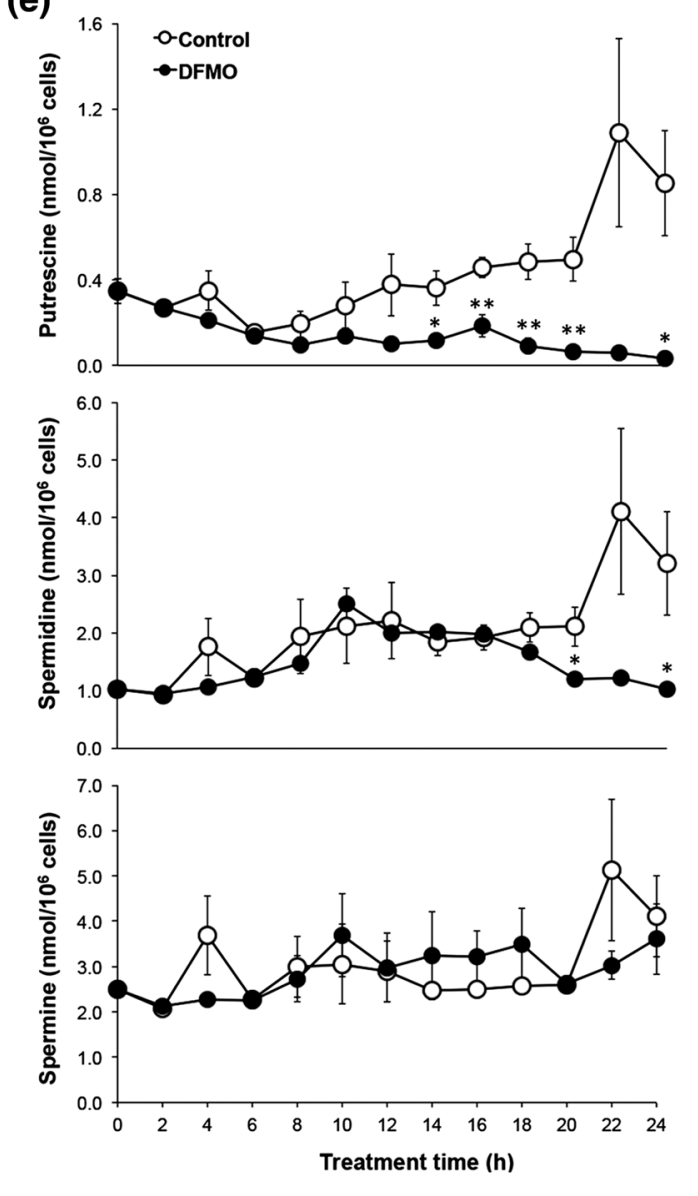


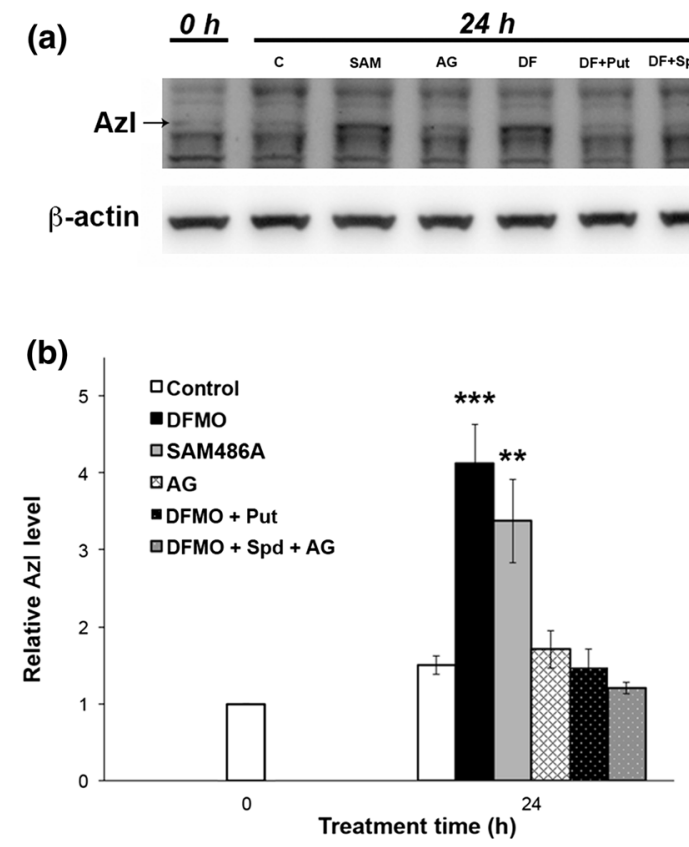

(d)
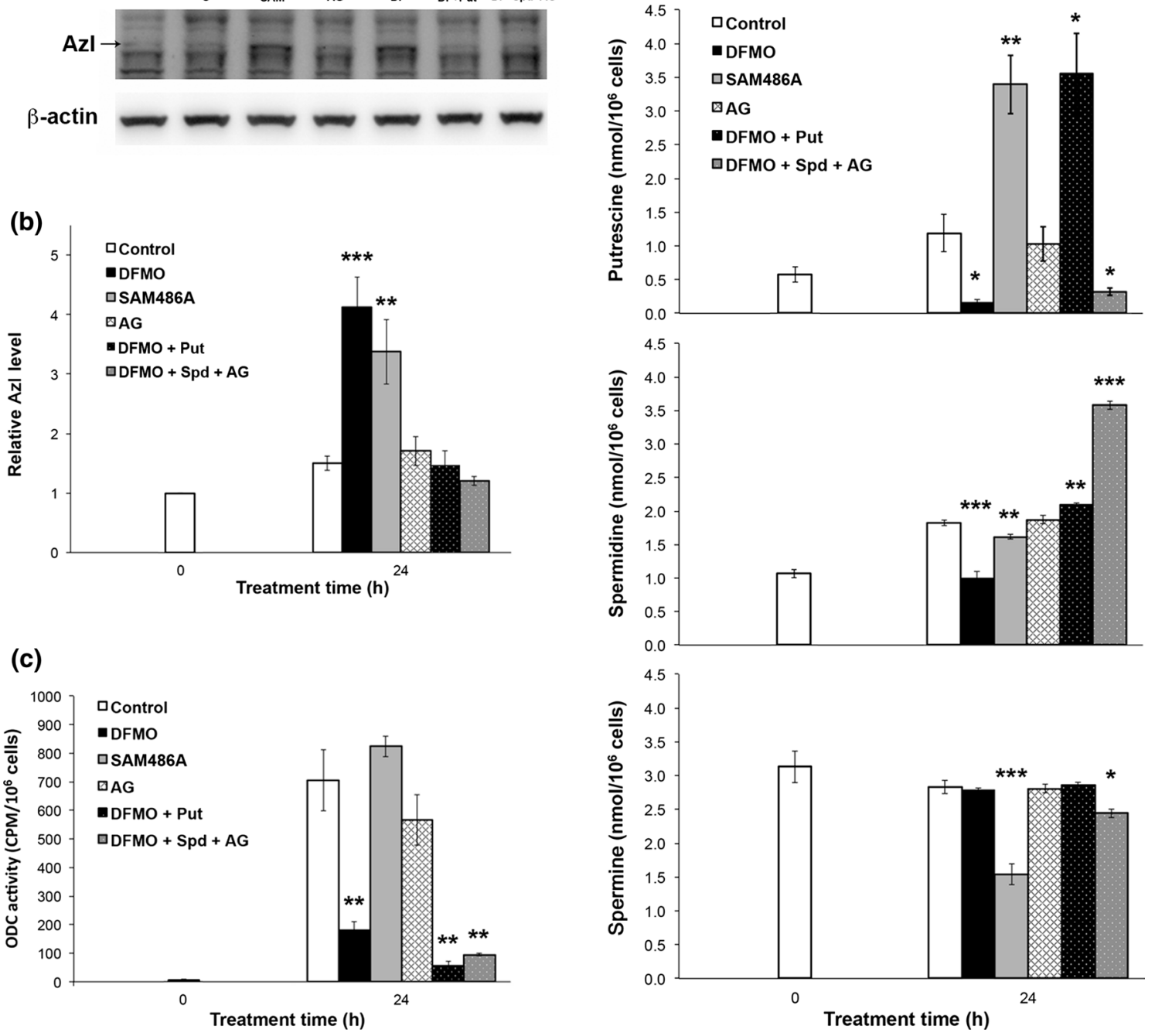

Fig. 3 Regulation of AzI by polyamines in JIMT-1 cells. Cells were seeded in the absence of compound (control) or in the presence of $1 \mathrm{mM}$ DFMO, $20 \mu \mathrm{M}$ SAM486A, $1 \mathrm{mM}$ aminoguanidine (AG), or $1 \mathrm{mM}$ DFMO (DF) and $100 \mu \mathrm{M}$ putrescine (put), or $1 \mathrm{mM}$ DFMO, $50 \mu \mathrm{M}$ spermidine (Spd) and $1 \mathrm{mM} \mathrm{AG}$ and then sampled at $24 \mathrm{~h}$ after seeding. AzI was determined by Western blot (a) and the data

caused by DFMO treatment, we examined if addition of putrescine or spermidine reversed the effect of the inhibitor on the AzI level seen after $24 \mathrm{~h}$ of treatment. As expected, addition of putrescine or spermidine to the cells treated with DFMO restored the cellular content of putrescine and/ or spermidine to control or above control values (Fig. 3d). Moreover, the addition of putrescine or spermidine prevented the DFMO-induced increase in cellular AzI content, (Fig. 3a, b). AG, which was added to the growth medium to prevent extracellular oxidation of spermidine by serum amine oxidases, had no effect on AzI expression, ODC activity or polyamine content per se (Fig. 3). The effect of SAM486A on the cellular AzI level was also analysed.

from three experiments were scanned using densitometry and presented as relative AzI expression (b). ODC activity was determined by a radiometric assay (c) and putrescine, spermidine and spermine contents (d) were determined by HPLC. Values are mean \pm SEM $(n=3-6)$. When not visible, the SEM bars are covered by the symbols. $* p<0.05 ; * * p<0.01 ; * * * p<0.001$ (compared to controls)

SAM486A is an inhibitor of S-adenosylmethionine decarboxylase, which together with ODC catalyses the key steps in the biosynthesis of polyamines (Pegg 2009). Treatment with SAM486A for $24 \mathrm{~h}$ resulted in an increased cellular level of AzI, which was similar to that observed after treatment with DFMO (Fig. 3a, b). The cellular putrescine content was also markedly increased, whereas the spermidine and particularly, the spermine content were decreased (Fig. 3d). Thus, the cellular expression of AzI appeared to be at least partly regulated by the polyamine pools. A decrease in the polyamine content thus resulted in an increase in AzI, which presumably caused an increase in the ODC level (due to the interaction of AzI with Az). 
(a)

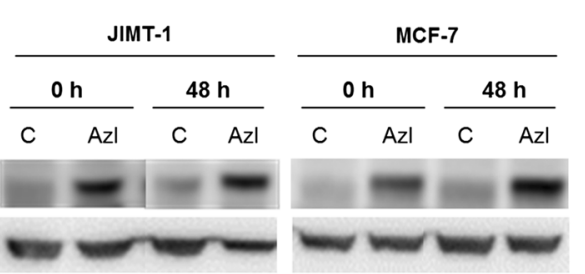

(b)

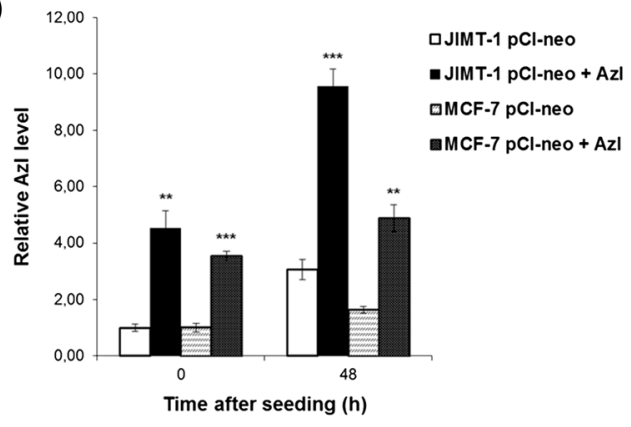

(c)
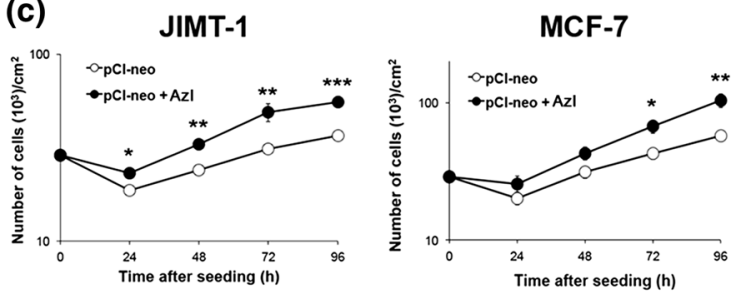

(d)

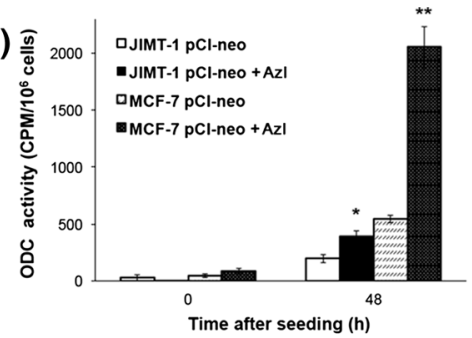

(e)

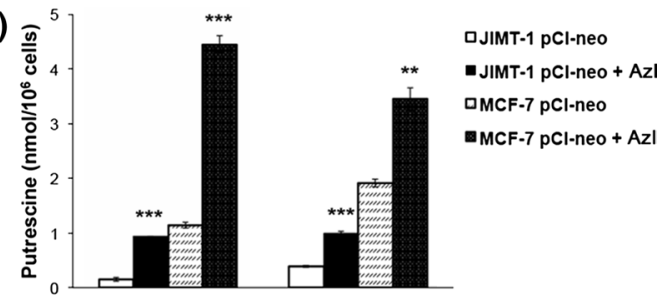

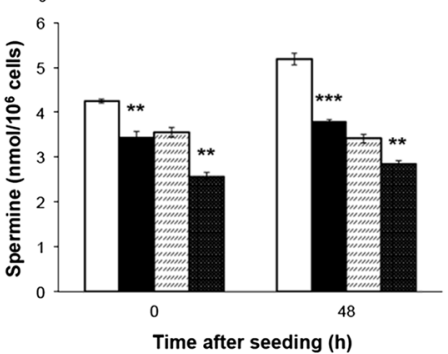

determined by counting in a hemocytometer (c). ODC activity was determined by a radiometric assay (d) and putrescine, spermidine and spermine contents (e) were determined by HPLC. Values are mean \pm SEM $(n=3-6)$. When not visible, the SEM bars are covered by the symbols. $* p<0.05 ; * * p<0.01 ; * * * p<0.001$ (compared to controls)

to the control cells (Fig. 4c). Increased AzI expression was also associated with an increase in ODC activity in the transfected cells $48 \mathrm{~h}$ after seeding (Fig. 4d). This was seen clearly in the AzI-expressing MCF-7 cells, where a more than fourfold increase in ODC activity was observed compared to the control cells $48 \mathrm{~h}$ after seeding (Fig. 4d). The cellular content of putrescine increased markedly; whereas that of spermine decreased in the cells expressing high levels of AzI compared to the control cells (Fig. 4e). Expression of AzI did not affect cellular spermidine content (Fig. 4e).

\section{Cellular localisation of AzI}

It has previously been reported that cellular localisation of AzI varies during the cell cycle, with a cytoplasmic 

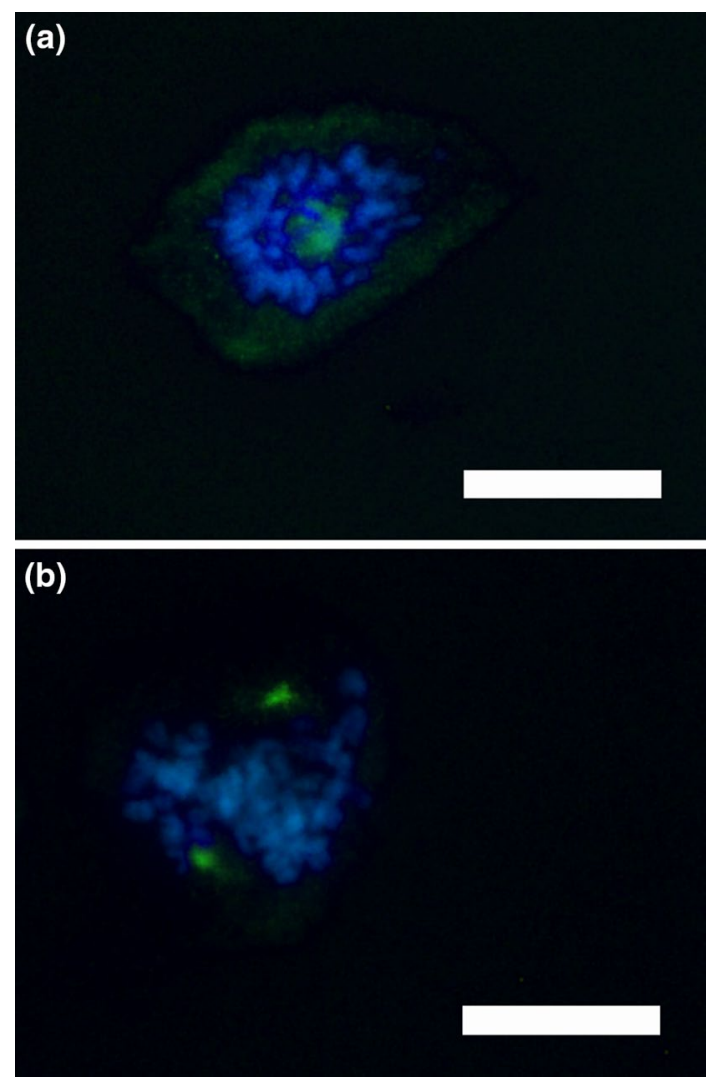

Fig. 5 Localisation of AzI during mitosis in JIMT-1 cells. Cells were seeded on poly-L-lysine-coated glass slides and fixed in paraformaldehyde. They were then stained with the primary AzI antibody and the secondary Alexa Fluor 488 antibody (green fluorescence) and DNA was stained with bisbenzimide (blue fluorescence). (a) Early mitosis. (b) Metaphase/anaphase. Size of bar in fluorescence microscopy images: $20 \mu \mathrm{m}$

localisation during interphase and a centrosomal localisation during mitosis, thereby indicating a role for AzI in the mitotic process (Mangold et al. 2008; Murakami et al. 2009). In the present study, we determined the intracellular localisation of AzI in JIMT- 1 cells $48 \mathrm{~h}$ after seeding, using immunofluorescence microscopy (Fig. 5). In early mitosis, before chromosomal alignment and centrosomal separation, AzI was found in the cytoplasm and in the central part of the nuclear area (Fig. 5a). In metaphase/anaphase, AzI was localised in a pattern that resembled the two centrosomes having chromosomes in between (Fig. 5b).

\section{Discussion}

As shown in the present study, the cellular level of AzI increased during the exponential growth of JIMT-1 cells. The increase probably reflects a rapid induction of AzI transcription after reseeding the cells in fresh medium. Nilsson et al. (2000) have demonstrated a rapid increase in AzI mRNA in mouse fibroblasts after growth stimulation by serum. Since binding of ODC to Az inhibits ODC activity, as well as stimulates its degradation, it is highly likely that the early increase in ODC activity seen in the JIMT-1 cells after seeding in fresh medium can be partly explained by a stabilisation/reactivation of the ODC protein caused by the sequestering of Az by AzI (Murakami et al. 1989; Nilsson et al. 2000). ODC activity started to decrease after $24 \mathrm{~h}$, whereas the AzI level remained elevated for $96 \mathrm{~h}$, after reseeding the cells in fresh medium. The ODC level (and activity) is dependent on a variety of factors which affect synthesis and degradation (e.g. ODC synthesis rate, levels of $\mathrm{Az}$ and $\mathrm{AzI}$ ) and thus the ODC activity may decrease even though the level of AzI remains elevated.

We also demonstrate that DFMO inhibits the polyamine biosynthetic pathway, while simultaneously increasing the AzI level in exponentially growing breast cancer cells, indicating a feedback control of AzI by the polyamines. Since the AzI level has been reported to fluctuate within the cell cycle with peaks during early $G_{1}$ and $G_{2} / M$ phases (Murakami et al. 2009), the observed increase in AzI level after DFMO treatment could also be due to an accumulation of cells in a specific phase (e.g. $G_{1}$ ) of the cell cycle caused by the ODC inhibitor. However, it was clear that the cell cycle progression was not affected by DFMO during the first $24 \mathrm{~h}$ of treatment, whereas the induction of AzI was observed as early as $16 \mathrm{~h}$ after start of treatment. Instead, the increase in AzI caused by DFMO appeared to correlate with a decrease in putrescine and/or spermidine levels in the cells. This was further supported by the reversible effect of putrescine and spermidine on DFMO-induced increase of AzI. Moreover, treatment with SAM486A resulted in a similar increase in cellular AzI content as that observed after DFMO treatment. However, the effects of the two inhibitors on cellular polyamine content differed. DFMO reduced putrescine and spermidine levels, whereas SAM486A reduced spermidine and spermine levels along with an increase in putrescine content. Thus, it would appear that the negative control of AzI is not exerted by a single polyamine. Instead, all of the three polyamines may have the capability to down-regulate AzI, although with different potencies. Murakami et al. (2009) have previously shown that the expression of AzI is negatively regulated by any of the polyamines in HTC cells.

Ivanov et al. (2008) demonstrated that all available sequences of vertebrate AzI mRNAs contain an upstream conserved coding region ( $\mathrm{uCC}$ ) of about 50 codons. The uCC lacks an in-frame AUG codon, but contains a conserved AUU near the $5^{\prime}$ end, which might serve as an initiation codon for the uCC. Using a luciferase reporter assay, Ivanov et al. (2008) were able to show that the uCC of mouse AzI mRNA mediates polyamine-induced repression of the downstream main open reading frame. In 
spermidine-supplemented cells, the expression of the main open reading frame was repressed 6.5-fold compared with that of polyamine-depleted (DFMO-treated) cells. However, this repression was essentially lost when the putative initiation codon of the $\mathrm{uCC}$ was mutated from AUU to a non-initiating UUU codon. Moreover, mutating the last 10 sense codons of the uCC gave similar results, eliminating polyamine-induced repression of main open reading frame translation. The results obtained in the present study together with those of Murakami et al. (2009), confirm that the expression of AzI in mammalian cells is regulated by polyamines. It is highly likely that this regulation occurs, at least partly, at the translational level by the mechanism suggested by Ivanov et al. (2008). AzI is reported to have a short half-life (Bercovich and Kahana 2004) and thus any change in the synthesis rate will result rapidly in a change in the level of the AzI protein. Murakami et al. (2009) were able to show that putrescine down-regulated AzI mainly at the translation level in HTC cells. Murakami et al. (2014) recently demonstrated that polyamines may also regulate AzI expression by affecting the transcription as well as the splicing pattern of the mRNA. They showed that polyamines, besides reducing the transcription of full-length AzI1 mRNA, actually increased the level of a splice variant with a premature termination codon (coding for an AzI lacking almost two-thirds of the $\mathrm{C}$-terminal region). In addition, polyamine depletion achieved after treatment with DFMO gave the opposite effect.

Increased levels of ODC and polyamines are distinctive features of rapid cell proliferation and of numerous forms of cancer (Wallace et al. 2003; Pegg 2006). ODC may be considered as a possible oncogene and overexpression of this enzyme has been demonstrated to induce cellular transformation in a variety of systems (Wallace et al. 2003; Pegg 2006; Shantz and Levin 2007). Thus, polyamine homeostasis is highly regulated and AzI appears to play an important role in this regulation. As shown in the present study, overexpression of AzI resulted in an increased cell proliferation, along with elevated levels of ODC and putrescine. Interestingly, the marked increase in ODC activity seen in the AzI-transfected cells during exponential growth (48 $\mathrm{h}$ after seeding) was not correlated with any major changes in polyamine levels, indicating that polyamine homeostasis is dependent on a variety of factors other than ODC activity [e.g. substrates for synthesis, other enzymes in the polyamine pathway (synthetic or degradative), cellular uptake or efflux of polyamines]. The increase in ODC activity was most likely related to a stabilisation of the enzyme due to the binding of $\mathrm{Az}$ to AzI. Keren-Paz et al. (2006) demonstrated that NIH3T3 mouse fibroblasts overexpressing AzI had elevated ODC and polyamine levels, and proliferated faster than control cells. Similar findings were obtained by Kim et al. (2006) using NIH3T3 cells and AT2.1 rat prostate carcinoma cells overproducing AzI. Keren-Paz et al. (2006) also demonstrated that AzI-overexpressing cells grew in the presence of low concentrations of serum, formed colonies in soft agar and gave rise to tumours when injected into nude mice, which all are attributes of transformed cells. In addition, AzI has been found to be up-regulated in a large number of cancers and thus may be regarded as a putative oncogene (Jung et al. 2000; Schaner et al. 2003; van Duin et al. 2005; Chin et al. 2007; Olsen and Zetter 2011). Conversely, silencing of AzI expression has been shown to reduce cell proliferation in vitro (Choi et al. 2005; Keren-Paz et al. 2006; Kim et al. 2006; Olsen et al. 2012), as well as repress tumour growth in vivo (Olsen et al. 2012). The effects of AzI most likely occur through the binding to $\mathrm{Az}$ and suppression of its functions. In addition to affecting the turnover of ODC, $\mathrm{Az}$ has been reported to stimulate the degradation of proteins important for cell cycling as well as centrosome duplication (Newman et al. 2004; Kasbek et al. 2010; Dulloo et al. 2010).

The results of the present study support the interesting observation of a centrosomal localisation of AzI during mitosis previously reported by Mangold et al. (2008) and Murakami et al. (2009). Also Az has been shown to be co-localised with the centrosome during mitosis (Mangold et al. 2008; Murakami et al. 2009). Interestingly, alterations in the AzI/Az ratio caused abnormalities in numbers of centrosomes in the cell, which further indicates a role for $\mathrm{Az}$ (and AzI) in centrosomal duplication (Mangold et al. 2008). It is conceivable that $\mathrm{Az}$ regulates the turnover of an essential centrosomal component. In fact, $\mathrm{Az}$ has been reported to stimulate the degradation of Aurora-A, which is a key protein in centrosome amplification (Lim and Gopalan 2007). However, more work is needed to identify the exact functions of $\mathrm{Az}$ and $\mathrm{AzI}$ in mitosis.

In conclusion, our findings strongly indicate that AzI plays essential roles in polyamine homeostasis and cell proliferation.

Acknowledgments We thank Ewa Dahlberg and Lena Thiman for expert technical help with cell culturing and HPLC, respectively. The authors acknowledge financial support from the Portuguese Foundation for Science and Technology-SFRH/BD/46364/2008 (PhD fellowship to T. M. S.), the Gunnar Nilssons Cancer Foundation, the Mrs Berta Kamprad Foundation and the Per-Eric and Ulla Schyberg Foundation. Heather Wallace was supported by a visiting scholarship from Lund University. We are grateful for the generous supply of AzI antibody and pcDNA3.1-AzI from Dr. Senya Matsufuji and Dr. Yasuku Murakami (Tokyo, Japan), and Dr. Leif Andersson (Helsinki, Finland), respectively.

Conflict of interest The authors declare that they have no conflict of interest.

Open Access This article is distributed under the terms of the Creative Commons Attribution License which permits any use, distribution, and reproduction in any medium, provided the original author(s) and the source are credited. 


\section{References}

Begg AC, McNally NJ, Shrieve DC, Karcher H (1985) A method to measure the duration of DNA synthesis and the potential doubling time from a single sample. Cytometry 6:620-626. doi:10.1002/cyto.990060618

Bercovich Z, Kahana C (2004) Degradation of antizyme inhibitor, an ornithine decarboxylase homologous protein, is ubiquitin-dependent and is inhibited by antizyme. J Biol Chem 279:54097-54102. doi:10.1074/jbc.M410234200

Chin SF et al (2007) High-resolution aCGH and expression profiling identifies a novel genomic subtype of ER negative breast cancer. Genome Biol 8:R215. doi:10.1186/gb-2007-8-10-r215

Choi KS, Suh YH, Kim WH, Lee TH, Jung MH (2005) Stable siRNAmediated silencing of antizyme inhibitor: regulation of ornithine decarboxylase activity. Biochem Biophys Res Commun 328:206-212. doi:10.1016/j.bbrc.2004.11.172

Dulloo I, Gopalan G, Melino G, Sabapathy K (2010) The antiapoptotic DeltaNp73 is degraded in a c-Jun-dependent manner upon genotoxic stress through the antizyme-mediated pathway. Proc Natl Acad Sci USA 107:4902-4907. doi:10.1073/ pnas.0906782107

Fredlund JO, Oredsson SM (1996) Impairment of DNA replication within one cell cycle in cells seeded in the presence of a polyamine biosynthesis inhibitor. Eur J Biochem 237:539-544

Fujita K, Murakami Y, Hayashi S (1982) A macromolecular inhibitor of the antizyme to ornithine decarboxylase. Biochem $\mathrm{J}$ 204:647-652

Gerner EW, Meyskens FL Jr (2004) Polyamines and cancer: old molecules, new understanding. Nat Rev Cancer 4:781-792. doi: $10.1038 / \mathrm{nrc} 1454$

Ivanov IP, Loughran G, Atkins JF (2008) uORFs with unusual translational start codons autoregulate expression of eukaryotic ornithine decarboxylase homologs. Proc Natl Acad Sci USA 105:10079-10084. doi:10.1073/pnas.0801590105

Jänne J, Williams-Ashman HG (1971) On the purification of L-ornithine decarboxylase from rat prostate and effects of thiol compounds on the enzyme. J Biol Chem 246:1725-1732

Jung MH et al (2000) Identification of differentially expressed genes in normal and tumor human gastric tissue. Genomics 69:281286. doi:10.1006/geno. 2000.6338

Kahana C (2009) Antizyme and antizyme inhibitor, a regulatory tango. Cell Mol Life Sci CMLS 66:2479-2488. doi:10.1007/ s00018-009-0033-3

Kanerva K, Makitie LT, Back N, Andersson LC (2010) Ornithine decarboxylase antizyme inhibitor 2 regulates intracellular vesicle trafficking. Exp Cell Res 316:1896-1906. doi:10.1016/j. yexcr.2010.02.021

Kasbek C, Yang CH, Fisk HA (2010) Antizyme restrains centrosome amplification by regulating the accumulation of Mps1 at centrosomes. Mol Biol Cell 21:3878-3889. doi:10.1091/mbc. E10-04-0281

Keren-Paz A, Bercovich Z, Porat Z, Erez O, Brener O, Kahana C (2006) Overexpression of antizyme-inhibitor in NIH3T3 fibroblasts provides growth advantage through neutralization of antizyme functions. Oncogene 25:5163-5172. doi:10.1038/ sj.onc. 1209521

Kim SW, Mangold U, Waghorne C, Mobascher A, Shantz L, Banyard J, Zetter BR (2006) Regulation of cell proliferation by the antizyme inhibitor: evidence for an antizyme-independent mechanism. J Cell Sci 119:2583-2591. doi:10.1242/jcs.02966

Lim SK, Gopalan G (2007) Antizyme1 mediates AURKAIP1dependent degradation of Aurora-A. Oncogene 26:6593-6603. doi:10.1038/sj.onc. 1210482
Lopez-Contreras AJ, Lopez-Garcia C, Jimenez-Cervantes C, Cremades A, Penafiel R (2006) Mouse ornithine decarboxylase-like gene encodes an antizyme inhibitor devoid of ornithine and arginine decarboxylating activity. J Biol Chem 281:30896-30906. doi:10.1074/jbc.M602840200

Lopez-Contreras AJ, Ramos-Molina B, Cremades A, Penafiel R (2008) Antizyme inhibitor 2 (AZIN2/ODCp) stimulates polyamine uptake in mammalian cells. J Biol Chem 283:20761-20769. doi:10.1074/jbc.M801024200

Mangold U, Hayakawa H, Coughlin M, Munger K, Zetter BR (2008) Antizyme, a mediator of ubiquitin-independent proteasomal degradation and its inhibitor localize to centrosomes and modulate centriole amplification. Oncogene 27:604-613. doi:10.1038/ sj.onc. 1210685

Matsufuji S, Matsufuji T, Miyazaki Y, Murakami Y, Atkins JF, Gesteland RF, Hayashi S (1995) Autoregulatory frameshifting in decoding mammalian ornithine decarboxylase antizyme. Cell 80:51-60

Mitchell JL, Judd GG, Bareyal-Leyser A, Ling SY (1994) Feedback repression of polyamine transport is mediated by antizyme in mammalian tissue-culture cells. Biochem J 299:19-22

Murai N, Murakami Y, Matsufuji S (2011) Protocols for studying antizyme expression and function. Methods Mol Biol 720:237267. doi:10.1007/978-1-61779-034-8_15

Murakami Y, Matsufuji S, Nishiyama M, Hayashi S (1989) Properties and fluctuations in vivo of rat liver antizyme inhibitor. Biochem J 259:839-845

Murakami Y et al (2009) The change of antizyme inhibitor expression and its possible role during mammalian cell cycle. Exp Cell Res 315:2301-2311. doi:10.1016/j.yexcr.2009.04.024

Murakami Y, Ohkido M, Takizawa H, Murai N, Matsufuji S (2014) Multiple forms of mouse antizyme inhibitor 1 mRNA differentially regulated by polyamines. Amino Acids 46:575-583. doi:10.1007/ s00726-013-1598-6

Newman RM, Mobascher A, Mangold U, Koike C, Diah S, Schmidt M, Finley D, Zetter BR (2004) Antizyme targets cyclin D1 for degradation. A novel mechanism for cell growth repression. J Biol Chem 279:41504-41511

Nilsson J, Grahn B, Heby O (2000) Antizyme inhibitor is rapidly induced in growth-stimulated mouse fibroblasts and releases ornithine decarboxylase from antizyme suppression. Biochem J 346:699-704

Nowotarski SL, Woster PM, Casero RA Jr (2013) Polyamines and cancer: implications for chemotherapy and chemoprevention. Expert Rev Mol Med 15:e3. doi:10.1017/erm.2013.3

Olsen RR, Zetter BR (2011) Evidence of a role for antizyme and antizyme inhibitor as regulators of human cancer. Mol Cancer Res 9:1285-1293. doi:10.1158/1541-7786.MCR-11-0178

Olsen RR, Chung I, Zetter BR (2012) Knockdown of antizyme inhibitor decreases prostate tumor growth in vivo. Amino Acids 42:549-558. doi:10.1007/s00726-011-1032-x

Pegg AE (2006) Regulation of ornithine decarboxylase. J Biol Chem 281:14529-14532. doi:10.1074/jbc.R500031200

Pegg AE (2009) S-adenosylmethionine decarboxylase. Essays in biochemistry 46:25-45. doi: $10.1042 / \mathrm{bse} 0460003$

Pegg AE, Casero RA Jr (2011) Current status of the polyamine research field. Methods Mol Biol 720:3-35. doi:10.1007/978-1-61779-034-8_1

Persson L (2009) Polyamine homoeostasis essays in biochemistry 46:11-24. doi:10.1042/bse0460002

Pitkanen LT, Heiskala M, Andersson LC (2001) Expression of a novel human ornithine decarboxylase-like protein in the central nervous system and testes. Biochem Biophys Res Commun 287:1051-1057. doi:10.1006/bbrc.2001.5703 
Rom E, Kahana C (1994) Polyamines regulate the expression of ornithine decarboxylase antizyme in vitro by inducing ribosomal frame-shifting. Proc Natl Acad Sci USA 91:3959-3963

Schaner ME et al (2003) Gene expression patterns in ovarian carcinomas. Mol Biol Cell 14:4376-4386. doi:10.1091/mbc. E03-05-0279

Seiler N, Knödgen B (1980) High-performance liquid chromatographic procedure for the simultaneous determination of the natural polyamines and their monoacetyl derivatives. J Chromatogr 221:227-235

Shantz LM, Levin VA (2007) Regulation of ornithine decarboxylase during oncogenic transformation: mechanisms and therapeutic potential. Amino Acids 33:213-223. doi:10.1007/ s00726-007-0531-2

Silva T, Andersson S, Sukumaran S, Marques M, Persson L, Oredsson S (2013) Norspermidine and novel Pd(II) and Pt(II) polynuclear complexes of norspermidine as potential antineoplastic agents against breast cancer. PloS One 8:e55651. doi:10.1371/journal. pone. 0055651
Snapir Z, Keren-Paz A, Bercovich Z, Kahana C (2008) ODCp, a brain- and testis-specific ornithine decarboxylase paralogue, functions as an antizyme inhibitor, although less efficiently than AzI1. Biochem J 410:613-619. doi:10.1042/BJ20071423

Suzuki T, He Y, Kashiwagi K, Murakami Y, Hayashi S, Igarashi K (1994) Antizyme protects against abnormal accumulation and toxicity of polyamines in ornithine decarboxylase-overproducing cells. Proc Natl Acad Sci USA 91:8930-8934

Tang H, Ariki K, Ohkido M, Murakami Y, Matsufuji S, Li Z, Yamamura K (2009) Role of ornithine decarboxylase antizyme inhibitor in vivo. Genes Cells 14:79-87. doi:10.1111/j.1365-2443.2008.01249.x

van Duin $M$ et al (2005) High-resolution array comparative genomic hybridization of chromosome arm 8q: evaluation of genetic progression markers for prostate cancer. Genes Chromosomes Cancer 44:438-449. doi:10.1002/gcc.20259

Wallace HM, Fraser AV, Hughes A (2003) A perspective of polyamine metabolism. Biochem J 376:1-14. doi:10.1042/BJ20031327 